\title{
PERCEPÇÃO DOS PROFESSORES DO ENSINO FUNDAMENTAL I QUANTO AOS IMPACTOS DA PANDEMIA DO COVID-19 NO PROCESSO DE APRENDIZAGEM INFANTIL
}

\author{
PERCEPTION OF PRIMARY SCHOOL TEACHERS I REGARDING THE \\ IMPACTS OF THE PANDEMIC OF COVID-19 ON THE PROCESS OF CHILD \\ LEARNING
}

\author{
Isabelle Cahino Delgado ${ }^{1}$ \\ Pâmela Pontes dos Santos ${ }^{2}$ \\ Maria Milena Sousa de Brito ${ }^{3}$
}

\begin{abstract}
RESUMO: Em virtude da pandemia do Coronavírus ocorrida no ano de 2020 e do isolamento social como forma de controle para o avanço da doença, as escolas precisaram ser fechadas e, assim, adotaram o ensino remoto emergencial para dar continuidade ao ano letivo. Partindo desse pressuposto, o objetivo desta pesquisa é apresentar, na percepção dos professores do Ensino Fundamental I, um panorama do processo de ensinoaprendizagem vivenciado ao longo da pandemia do COVID-19 por meio da modalidade remota. O estudo se caracteriza por ser do tipo transversal, exploratório e de caráter quali-quantitativo. Participaram 11 professoras do Ensino Fundamental I de instituições privadas de ensino. A coleta de dados ocorreu através de um questionário online divulgado previamente nas redes sociais. Nos resultados, foi observado que os professores conseguem identificar os alunos com dificuldade de aprendizagem, e que estes tinham acesso aos aparelhos eletrônicos mas não sabiam como usá-los com intuito pedagógico. Algumas escolas não ofereceram esse suporte ao docente, por meio de capacitações para o uso dos aparelhos e das novas plataformas para as transmissões das aulas, por exemplo. O papel da família neste processo foi de suma importância para uma aprendizagem eficaz das crianças. Ainda assim, foi notado mudanças comportamentais durante este período. A quarentena e o ensino remoto trouxeram impactos negativos na saúde mental dos professores que, por sua vez, não apresentam segurança quanto à eficácia do ensino remoto emergencial. Dessa forma, a presente pesquisa revelou de forma sucinta, na visão dos professores, os aspectos positivos e as fragilidades do ensino remoto emergencial e, ainda, seus impactos na aprendizagem infantil. No mais, apresentou limitações quanto ao número de participantes e espera-se que novos estudos sejam desenvolvidos com um número maior de voluntários.
\end{abstract}

PALAVRAS-CHAVE: Professores escolares. COVID-19. Educação a distância.

ABSTRACT: Due to the Coronavirus pandemic that occurred in 2020 and social isolation as a way of controlling the disease, schools had to be closed and, thus, adopted emergency remote education to continue the school year. Based on this assumption, the objective of this research is to present, in the perception of elementary school teachers, an overview of the teaching-learning process experienced along the COVID-19 pandemic through remote modality. The study is characterized by being cross-sectional, exploratory and quali-quantitative in character. 11 elementary school teachers from private educational institutions participated. Data collection occurred through an online questionnaire previously published on social networks. In the results, it was observed that teachers can identify students with learning difficulties, and that they had access to electronic devices but not how to use them for pedagogical purposes. Some schools did not offer this support to teachers, through training with the use of devices and new platforms for the transmission of classes, for example. The role of the family in this process was of paramount importance for effective learning of children. Still, behavioral changes were observed during this period. Quarantine and remote education have had negative impacts on the mental health of teachers who, in turn, are not safe about the effectiveness of emergency remote education. Thus, this research briefly revealed, in the view of teachers, the positive aspects and weaknesses of emergency remote education and also its impacts on child

\footnotetext{
${ }^{1}$ Docente do Departamento de Fonoaudiologia da UFPB. Líder do Núcleo de Estudos em Linguagem e Funções Estomatognáticas (NELF/UFPB/CNPq). Doutora em Linguística pelo PROLING. E-mail: fgaisabelle@hotmail.com. Orcid: https://orcid.org/0000-0002-0800-559X

$\frac{2}{2}$ Graduanda de Fonoaudiologia da UFPB. E-mail: pamela.pontes@,hotmail.com Orcid: https://orcid.org/00000003-0505-5628

${ }^{3}$ Graduanda de Fonoaudiologia da UFPB. E-mail: eumilenasousaa@gmail.com Orcid: https://orcid.org/00000003-3336-0136
} 
Volume 16 - Número 1 - jan/jul de 2021

learning. Moreover, it presented limitations regarding the number of participants and it is expected that further studies will be developed with a larger number of volunteers.

KEYWORDS: School teachers. COVID-19. Distance education.

\section{Introdução}

Um novo vírus (Sars-CoV-2) que preocupa as pessoas mundialmente atinge o solo brasileiro em fevereiro de 2020. O Coronavírus provoca a doença COVID-19, transmitido, principalmente, através de gotículas e pode manifestar variados níveis de sintomas (assintomáticos, oligossintomáticos ou sintomáticos). Um mês após o primeiro caso confirmado, o Estado declara transmissão comunitária do Coronavírus e, portanto, como medida preventiva o isolamento domiciliar a fim de frear o número de casos (BRASIL, 2020a).

Desde então, vive-se o incerto. Por causa do isolamento social aulas presenciais foram suspensas, muitos trabalhadores aderiram ao home office, outros ficaram desempregados. Essas situações impactaram drasticamente na economia desencadeando maior vulnerabilidade social, além de prejudicar a saúde mental das pessoas (SOUZA et al., 2021).

A partir da portaria número 343 publicada no dia 17 de março de 2020, foi autorizada a substituição das aulas presenciais para meio digital com o objetivo de não prejudicar o ano letivo dos mesmos (BRASIL, 2020b). Porém, foi observado que não foram todas as escolas que adotaram o ensino remoto, sendo assim, a Organização das Nações Unidas para a Educação, a Ciência e a Cultura (UNESCO) apresentaram dados que o fechamento das escolas afetou a continuidade do ensino para $70 \%$ dos estudantes trazendo consequências graves no processo de ensino-aprendizagem (UNESCO, 2020).

Por conseguinte, os professores tiveram que passar por adaptações rápidas, modificar o local de descanso para ser o novo ambiente de trabalho, adquirir novos equipamentos, compreender o uso das plataformas digitais, acesso à internet de qualidade, apresentar metodologias eficazes para a nova realidade, além de dividir a atenção com afazeres domésticos e atividades laborais (SOUZA et al., 2021). Apesar dessas adaptações, é notório, pelos professores, que apenas 30\% dos alunos estejam presentes nas aulas online. Com o tempo, o interesse pelas aulas reduz e é necessário tanto pelo alunado quanto professores a busca constante pelo conhecimento de forma interativa (ALMEIDA; DALBEN, 2020).

Todavia, pode-se perceber na literatura que o Ensino Remoto Emergencial (ERE) durante a pandemia possibilitou a continuidade do ano letivo, aproximação entre alunos e professores, maiores possibilidades de recursos digitais para facilitar no entendimento do assunto, maior flexibilização de horários, dentre outras (ALVES et al., 2020).

Importante destacar que conceitualmente existe diferenças em relação aos termos Educação a distância (EaD) e o Ensino Remoto Emergencial (ERE). No EaD, é necessário previamente um preparo e cuidado na elaboração dos conteúdos pedagógicos para os Ambientes Virtuais de Aprendizagem (AVA), tendo em vista que a aprendizagem do aluno ocorre de maneira autônoma. Sobre o ERE, pode-se entender como adaptações pedagógicas necessárias, previamente utilizadas na $\mathrm{EaD}$, para continuidade do processo de ensino-aprendizagem não presenciais, cujo tais profissionais não tiveram preparo adequado para exercer suas funções com o uso das tecnologias de informação (SOUZA et al., 2021).

$\mathrm{Na}$ literatura encontra-se que a mudança abrupta para o ensino remoto em decorrência da pandemia trouxe mudanças na forma de ensinar para os professores que tiveram que mudar suas estratégias como uso de mapas mentais durante as aulas, discussão de artigos, reflexões sobre o cenário atual. Com isso, pode-se observar que a base para a construção do ensino remoto emergencial foi o diálogo (MORAES et al., 2020). 
Sendo assim, o estudo justifica-se pela necessidade de compreender sob a ótica docente quais adaptações foram necessárias, o impacto dessas mudanças na saúde mental, o contexto entre escola e professores, a eficácia do processo de ensino-aprendizagem, além de elencar as potencialidades e desafios do ensino remoto emergencial.

Diante do exposto, a presente pesquisa tem como objetivo apresentar, na percepção dos professores do Ensino Fundamental I, um panorama do processo de ensino-aprendizagem vivenciado ao longo da pandemia do COVID-19 por meio da modalidade remota.

\section{Metodologia}

O presente estudo se caracteriza por ser do tipo transversal, exploratório e de caráter quali-quantitativo. O mesmo foi aprovado pelo Comitê de Ética em Pesquisa com Seres Humanos da instituição de origem, sob processo de número de protocolo 4.473.160. Todos os sujeitos que participaram assinaram o Termo de Consentimento Livre e Esclarecido - TCLE antes de responderem o questionário relacionado à pesquisa, estando de acordo com o recomendado pela resolução 466/12 da Comissão Nacional de Ética em Pesquisa (CONEP).

Participaram da pesquisa 11 professoras polivalentes do ensino fundamental (anos iniciais). Os docentes participantes se enquadraram nos seguintes critérios de elegibilidade: ser professor polivalente do ensino fundamental I e ministrar aulas em instituições privadas.

Por meio de uma divulgação prévia nas redes sociais (Instagram e WhatsApp) foi disseminado o questionário desenvolvido exclusivamente para presente pesquisa (em anexo). Nos convites de recrutamento dos participantes continham o título da pesquisa e os requisitos para participação na mesma, além da indicação de onde encontrar o questionário. As perguntas foram respondidas via Google Forms no período de 23 de Novembro de 2020 a 15 de Dezembro de 2020.

O questionário foi dividido em 6 seções, sendo elas: dados de identificação (3 itens), perfil sociodemográfico ( 9 itens), recursos para o Ensino a Distância (4 itens), adaptações da escola para o ERE (17 itens), saúde mental (6 itens) e fatores comportamentais ( 7 itens).

Os dados foram analisados qualitativamente com base nas respostas encontradas pelos professores. E a análise quantitativa por meio da pontuação a partir do questionário online. Esses dados foram tabulados em uma planilha no Microsoft Excel, versão 2003. A partir deste, foram extraídos os resultados expressos através de quadros e tabelas.

A amostra foi composta por 11 pessoas do sexo feminino e caracterizada por três variáveis, sendo elas: idade, número de escolas onde trabalham e número de alunos para os quais lecionam atualmente.

Dessa forma, a idade das professoras variou entre 23 a 43 anos, com média aritmética de 34,28 anos. $9(81,9 \%)$ docentes participantes lecionam apenas em uma instituição. E, 4 $(36,4 \%)$ professoras lecionam para menos de 20 alunos.

\section{Resultados}

Quanto aos resultados, foi observado que nas escolas onde os professores lecionam existem alunos com dificuldades de aprendizagem $(n=10-90,9 \%)$.

Em relação aos recursos para o ERE, pode-se encontrar as variáveis dispostas na tabela 1 sobre os equipamentos eletrônicos, lembrando que os professores poderiam marcar mais de uma opção se fizesse o uso de mais de um equipamento para ministrar suas aulas. 
Volume 16 - Número 1 - jan/jul de 2021

Tabela 1. Equipamentos eletrônicos utilizados nas aulas remotas

\begin{tabular}{lll}
\hline Equipamentos eletrônicos & $\mathbf{N}$ & $\mathbf{\%}$ \\
\hline Celular & 9 & 81,8 \\
\hline Notebook & 8 & 72,7 \\
\hline Computador & 4 & 36,4 \\
\hline Tablet & 1 & 9,1
\end{tabular}

Fonte: Dados da pesquisa (2021)

Todos os professores $(\mathrm{n}=11-100 \%)$ afirmaram que dispuseram de internet de qualidade para ministrar as aulas. E, a maioria dos professores $(n=9-81,8 \%)$ adquiriram novos equipamentos como ring light, suporte para celular, dentre outros para melhorar a qualidade de suas aulas. Apenas alguns professores $(n=4-36,4 \%)$ dispõem de um ambiente totalmente calmo e silencioso para ministrar suas aulas, 5 professores $(45,5 \%)$ tem um ambiente parcialmente silencioso e 2 docentes $(18,2 \%)$ precisam lecionar em ambientes ruidosos.

$\mathrm{Na}$ tabela 2 é possível encontrar quais plataformas estão sendo utilizadas para ministrar os conteúdos aos alunos.

Tabela 2. Adaptações para o ensino remoto e plataformas utilizadas

\begin{tabular}{lll}
\hline Variáveis & N & \% \\
\hline Formato das aulas & & \\
\hline Aulas Síncronas + Atividades Assíncronas & 8 & 72,7 \\
\hline Apenas aulas síncronas & 2 & 9,2 \\
\hline Apenas atividades assíncronas & 1 & \\
\hline Plataformas para o ensino síncrono & & 81,8 \\
\hline Google Meet & 9 & 9,1 \\
\hline Facebook & 1 & \\
\hline Plataformas para atividades assíncronas & & 36,4 \\
\hline Google Classroom & 4 & 36,4 \\
\hline WhatsApp & 4 & 9,1 \\
\hline Facebook & 1 & \\
\hline
\end{tabular}

Fonte: Dados da pesquisa (2021)

Durante a pandemia, foi possível observar que as escolas precisaram passar por adaptações para o ensino remoto. Como pode-se observar na tabela 3,4 professores $(36,4 \%)$ afirmaram que a instituição de ensino ofereceu curso de capacitação quanto ao uso dos aparelhos eletrônicos e a maioria dos professores $(n=6-54,5 \%)$ afirmaram que receberem instruções em relação ao uso das plataformas digitais. Para planejamento das aulas, parte das docentes $(n=5-45,5 \%)$ informaram que essas formações ocorreram de forma online e a maioria $(n=7-63,3 \%)$ confirmaram que as formações correspondem aos objetivos curriculares.

Tabela 3. Adaptações da escola para o ensino remoto

\begin{tabular}{lll}
\hline Variáveis & N & \% \\
\hline Capacitações & & \\
\hline Quanto ao uso de aparelhos eletrônicos & 4 & 36,4 \\
\hline Quanto ao uso de plataformas digitais & 6 & 54,5 \\
\hline Formações & & \\
\hline
\end{tabular}


Volume 16 - Número 1 - jan/jul de 2021

\begin{tabular}{lll}
\hline Para planejamento de aulas de forma online & 5 & 45,5 \\
\hline $\begin{array}{l}\text { Para planejamento de aulas de forma } \\
\text { presencial }\end{array}$ & & 18,2 \\
\hline Para planejamento de aulas não ocorrem & 4 & 36,4 \\
\hline Correspondem aos objetivos curriculares & 7 & 63,6 \\
\hline
\end{tabular}

Fonte: Dados da pesquisa (2021)

A maioria dos docentes ( $\mathrm{n}=8-72,7 \%)$ afirmaram que conseguiram cumprir o conteúdo programático proposto para o ano de $2020 \mathrm{com}$ base nas ideias fundamentais alinhadas à Base Nacional Comum Curricular (BNCC).

O público participante da pesquisa pôde avaliar a qualidade do ERE, os resultados se encontram na tabela 4. Para 6 professores $(54,5 \%)$ o alcance das propostas traçadas ao longo do ERE foi bom. Em relação aos alunos com dificuldades de aprendizagem, 10 docentes $(90,9 \%)$ apontaram que esses alunos estão conseguindo aprender parcialmente o que foi direcionado. No geral, os professores $(n=5-45,5 \%)$ disseram que houveram mudanças comportamentais por parte dos alunos neste período de pandemia e que as famílias ( $\mathrm{n}=6-54,5 \%)$ estão participando efetivamente no processo de ensino-aprendizagem de seus alunos.

Tabela 4. Avaliação docente quanto a aprendizagem e ao comportamento dos discentes

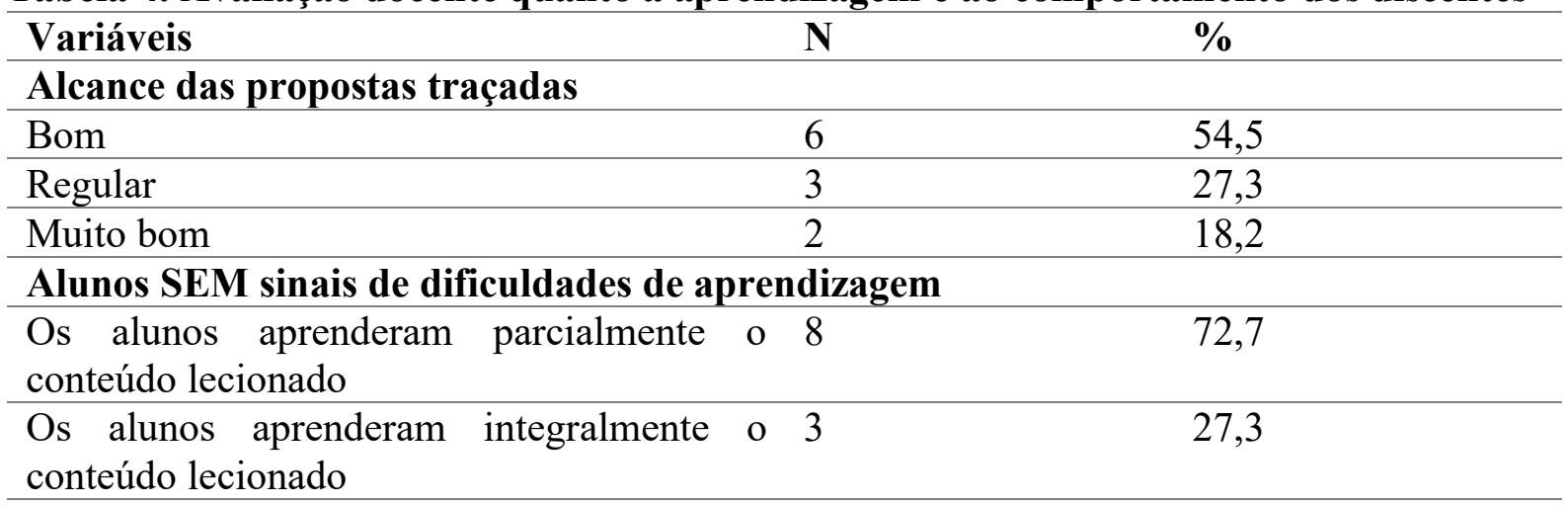

\begin{tabular}{|c|c|}
\hline Alunos COM sinais de dificuldades de aprendi & \\
\hline $\begin{array}{l}\text { Os alunos aprenderam parcialmente } \\
\text { conteúdo lecionado }\end{array}$ & 90,9 \\
\hline $\begin{array}{l}\text { Não tive alunos com dificuldades de } 1 \\
\text { aprendizagem }\end{array}$ & 9,1 \\
\hline
\end{tabular}

Mudanças comportamentais durante o ERE

Foi encontrado mudanças comportamentais $\quad 5 \quad 45,5$

Alunos se mantiveram atentos e $3 \quad 27,3$ participativos

Participação das famílias no processo de ensino-aprendizagem

As famílias foram muito participativas $\quad 6 \quad 54,5$

As famílias não participaram $\quad 3 \quad 27,3$

As famílias tiveram uma participação regular $2 \quad 18,2$

Fonte: Dados da pesquisa (2021)

Através do questionário também foi possível analisar que os professores $(n=8-72,7 \%)$ tiveram que conciliar as atividades acadêmicas com outras atividades domésticas como limpeza da sua residência e a preparação das refeições. 
As questões de saúde mental foram avaliadas através da escala likert, onde temos 0 para discordo totalmente e 5 para concordo totalmente. Na tabela 5 , pode-se visualizar um resumo de todas as questões e qual a pontuação a maioria dos professores marcaram. Como pode-se ver, a pandemia afetou consideravelmente a saúde mental dos professores participantes da pesquisa.

Tabela 5. Avaliação da saúde mental através da escala likert

\begin{tabular}{lll}
\hline Variáveis & $\begin{array}{l}\text { Resposta marcada } \\
\text { pela maioria }\end{array}$ & $\begin{array}{l}\text { Quantitativo } \\
\text { professores } \\
\mathrm{n}=5-45,5 \%\end{array}$ \\
\hline $\begin{array}{l}\text { Consigo manter uma rotina de trabalho } \\
\text { saudável }\end{array}$ & 4 & $\mathrm{n}=4-36,4 \%$ \\
\hline Possuo mudanças de humor repentinas & 5 & $\mathrm{n}=3-27,3 \%$ \\
\hline Na maior parte do tempo sinto-me ansioso & 5 & $\mathrm{n}=4-36,4 \%$ \\
\hline $\begin{array}{l}\text { Sinto-me inseguro quanto a aprendizagem } \\
\text { dos meus alunos no ERE. }\end{array}$ & 5 & $\mathrm{n}=4-36,4 \%$ \\
\hline $\begin{array}{l}\text { Sofri abalos na minha saúde mental ao longo } \\
\text { da pandemia }\end{array}$ & 5 & \\
\hline $\begin{array}{l}\text { Fonte: Dados da pesquisa (2021) } \\
\text { Pon }\end{array}$ & &
\end{tabular}

Com relação aos fatores comportamentais foi visto que os professores não se sentem motivados a ministrar suas aulas online diariamente e que eles têm de dispor mais concentração para realização de suas atividades neste período. Quanto a memória, alguns professores relataram sofrer picos de esquecimento. A tabela 6 mostra os dados e as variáveis detalhadamente, lembrando que, para este tópico também foi utilizada a escala likert.

Tabela 6. Alteração de fatores comportamentais durante a pandemia

\begin{tabular}{lll}
\hline Variáveis & $\begin{array}{l}\text { Resposta marcada } \\
\text { pela maioria }\end{array}$ & $\begin{array}{l}\text { Quantitativo } \\
\text { professores }\end{array}$ \\
\hline Sinto-me motivado a lecionar diariamente & 2 & $\mathrm{n}=3-27,3 \%$ \\
\hline Tenho que esforçar para me concentrar & 4 & $\mathrm{n}=4-36,4 \%$ \\
durante meu período de trabalho. & 5 & $\mathrm{n}=4-36,4 \%$ \\
\hline Quanto a minha memória, costumo sofrer & 1 & $\mathrm{n}=3-27,3 \%$ \\
picos de esquecimento constantemente. & 3 & $\mathrm{n}=3-27,3 \%$ \\
& 5 & $\mathrm{n}=3-27,3 \%$ \\
\hline $\begin{array}{l}\text { Sinto que me esforço um pouco mais para } \\
\text { manter o foco, pelo fato de usar aparelhos }\end{array}$ & 5 & $\mathrm{n}=4-36,4 \%$ \\
eletrônicos. & & \\
\hline
\end{tabular}

Fonte: Dados da pesquisa (2021)

Em um espaço específico e aberto, os professores puderam expor seu ponto vista em relação a pandemia. Pode-se verificar abaixo recortes da fala de algumas docentes sendo possível observar que elas tiveram que passar por esse momento de adaptação de forma rápida e eficaz pensando em todo o processo de ensino-aprendizagem desses alunos e que não foi um processo fácil pelas dificuldades ao longo do percurso.

Professora 1: "Razoável!! A distância entre os alunos e professores nos impossibilita de ter um acompanhamento com excelência e dispor de nossas teologias com base apenas em aulas a distância, sem contato físico, sem o ambiente escolar, gerou uma série de adaptações, as quais no meu ponto de vista não foram totalmente alcançadas por todos." 
Professora 2: "Acredito que o ensino à distância seja bom. Mas, não da forma que aconteceu esse ano. Fomos obrigados a lecionar dessa forma, sem preparo psicológico. Diferente de quando optamos pelo ensino a distância e nos preparamos para tal."

Professora 3: "Ninguém estava preparado para uma pandemia, e muito menos para aulas remotas. Acredito que o professor precisa ser melhor orientado quanto ao ensino e a forma como ensinar a distância, principalmente nas séries de pré alfabetização e alfabetização."

Professora 4: "É um ensino onde família e escola tentam se adaptar ao novo, onde a família se torna o grande responsável de dar o suporte aos filhos forçadamente, onde muitos não tem responsabilidade pela vida escolar do filho."

Professora 8: "Um processo que foi necessário trazendo dificuldades para ambas as partes, mas também grandes aprendizados."

\section{Discussão}

Em decorrência da pandemia do COVID-19, o sistema educacional no mundo sofreu alterações. As escolas tiveram que ser fechadas para evitar a contaminação em massa e emergencialmente adotaram o ensino remoto para que os alunos não fossem prejudicados. Foram 9 meses de ensino remoto e distanciamento social no ano de 2020, os quais prejudicaram as habilidades sociais, emocionais, comportamentais, educacionais, dentre outras (FONSECA; SGANZERLA; ENÉAS, 2020).

Analisando os resultados da presente pesquisa, pode-se afirmar que as professoras apresentaram boa percepção para identificar crianças com Transtorno Específico de Aprendizagem ou dificuldade de aprendizagem em suas turmas. Esse achado corrobora com o estudo de Gonçalves e Crenitte (2014) no qual apresenta que a maioria das professoras tinham conhecimentos acerca da dificuldade.

A American Psychiatric Association (APA, 2014), por meio do DSM - V, coloca o Transtorno Específico de Aprendizagem como:

(...) dificuldades persistentes para aprender habilidades acadêmicas fundamentais, com início durante os anos de escolarização formal. Habilidades acadêmicas básicas incluem leitura exata e fluente de palavras isoladas, compreensão da leitura, expressão escrita e ortografia, cálculos aritméticos e raciocínio matemático. (APA, 2014, p.68)

Além desses aspectos citados, a APA (2014), aponta determinados critérios diagnósticos para os Transtornos Específicos de Aprendizagem, pela presença de prejuízos nas habilidades acadêmicas, que se encontram abaixo do esperado para a idade cronológica do indivíduo. Por fim, considera que as dificuldades de aprendizagem não podem ser explicadas por deficiências intelectuais, acuidade visual ou auditiva não corrigida, outros transtornos mentais ou neurológicos, adversidade psicossocial, falta de proficiência na língua de instrução acadêmica ou instrução educacional inadequada. Por este motivo, esses critérios diagnósticos devem ser preenchidos com base em uma síntese clínica da história do indivíduo (do desenvolvimento, médica, familiar, educacional), em relatórios escolares e em avaliação psicoeducacional.

Um estudo recente mostrou que a maior parte das famílias brasileiras utilizam o smartphone como principal meio de acesso à internet, concordando com os dados dessa pesquisa, uma vez que 9 professoras apontaram utilizar o celular como principal meio de ministrar suas aulas (JOYE; MOREIRA; ROCHA, 2020).

Porém, os docentes afirmaram que houve a necessidade de adquirir novos equipamentos a fim de melhorar a qualidade das aulas e a aprendizagem dos alunos. Outro ponto importante 
para o ensino remoto é dispor de internet de qualidade e este não foi um fator de impedimento para a condução das aulas pelos participantes da pesquisa.

Além das novidades tecnológicas inseridas no ambiente de trabalho, os professores tiveram que se adaptar às novas plataformas para transmitir suas aulas. A mais utilizada para os momentos síncronos pelo público-alvo da presente pesquisa foi o Google Meet. No estudo de Leite, Lima e Carvalho (2020) os professores também utilizaram a mesma plataforma como meio principal, além disso foram utilizadas algumas redes sociais como o WhatsApp e Facebook em alguns casos por ser de fácil domínio das crianças e dos próprios docentes.

A partir desses dados, deve-se dar destaque à formação continuada desses professores que não nasceram na Geração $\mathrm{Z}$ e, portanto, não apresentam grandes conhecimentos acerca de todas as tecnologias atuais. Se, anteriormente, o público em questão fosse em busca de ferramentas que os atualizassem para os instrumentos contemporâneos, poderia ter facilitado o processo de adaptação ao ensino remoto emergencial (LEITE; LIMA; CARVALHO, 2020).

Analisando os dados desta pesquisa, algumas escolas ofertaram capacitações às professoras quanto ao uso das plataformas e dos aparelhos eletrônicos. Porém, essa não foi a realidade de todas e em alguns discursos foi possível analisar que, na opinião delas, caso houvesse um preparo maior frente ao ensino remoto e todas às tecnologias que o acompanha, poderia ter melhorado a qualidade do processo de ensino-aprendizagem de seus alunos.

O estudo de Corrêa, Nunes e Dias-Trindade (2020) seguiu na mesma perspectiva da presente pesquisa, uma vez que os autores relataram o conhecimento com as Tecnologias Digitais da Informação e Comunicação (TDIC) por parte dos professores, mas eles ainda não tinham utilizado tais instrumentos com intuito pedagógico.

Embora perante todas as dificuldades apontadas anteriormente para o ensino remoto, foi possível dar continuidade ao ano letivo, evitando maiores prejuízos aos alunos. $54,5 \%$ das professoras apontaram que foi bom o alcance das propostas traçadas para o período remoto. Em uma pesquisa, foi visto que os professores sentiam confiança para ministrar suas aulas remotas por ter conhecimento prévio das tecnologias, porém sentiram dificuldades em avaliar o nível de aprendizagem de seus alunos (SOUZA et al., 2021).

Outro ponto importante e percebido pelas professoras foi a mudança de comportamento de seus alunos que relataram estar com o limiar de irritabilidade menor, choros constantes, falta de motivação para assistir às aulas e quando assistiam, estavam dispersos. O desgaste físico e psicológico dos professores e dos pais também foi analisado no estudo de Medeiros et al. (2020). Dessa forma, é imprescindível avaliar todo o contexto entre família-escola-aluno e desenvolver uma rede de apoio pensando sempre em beneficiar as crianças (MEDEIROS et al., 2020).

O apoio familiar está sendo crucial na aprendizagem das crianças neste período como suporte pedagógico e emocional. A maioria das professoras desta pesquisa afirmaram que as famílias foram bastante participativas no processo. Barros e Menezes (2021) pontuam que a relação entre escola-família melhorou consideravelmente neste tempo pelas participações nas práticas pedagógicas e apoio mútuo. Eles afirmam, ainda, que este deve ser um ponto positivo que perdure após o período pandêmico.

Embora tenham sido pontuadas questões positivas acerca do ERE anteriormente, os professores tiveram que adaptar o seu ambiente de descanso para o trabalho e, muitas vezes, dividir as atividades laborais com as atividades domésticas.

Além disso, é válido pensar na saúde mental dos professores. Em virtude da pandemia, todos ficaram sem a possibilidade de sair de casa e ter interações sociais que acabaram restringindo as atividades de lazer e, consequentemente, trariam abalos biopsicossociais. Porém, são escassas as publicações em relação à saúde mental com este público-alvo e nesta perspectiva de investigação. 
Volume 16 - Número 1 - jan/jul de 2021

\section{Considerações finais}

O presente estudo mostra, de forma geral, um panorama sobre o ensino remoto emergencial na visão dos professores. Foram vistas e analisadas as mudanças pedagógicas no ensino remoto emergencial e o impacto destas no processo de ensino-aprendizagem dos alunos da educação infantil.

Graças ao ensino remoto foi possível dar continuidade ao ano letivo para que os alunos não saíssem prejudicados, mas as professoras tiveram que aprender a usar as tecnologias como instrumento de trabalho, aderir às plataformas para transmitir suas aulas, adaptar o seu lar para atividades laborais, dentre outras. Porém, embora as metas traçadas inicialmente tenham sido satisfatórias, os professores afirmaram que os alunos apresentaram algumas dificuldades para compreender os assuntos.

Observou-se que o apoio familiar foi essencial em todo o processo de ensinoaprendizagem durante a pandemia do COVID-19 e com uso das tecnologias pelas crianças. A relação entre escola e família tende a melhorar no período pós pandêmico pela boa interação e resultados satisfatórios vivenciados neste momento.

A presente pesquisa apresentou limitações quanto ao número de participantes e esperase que novos estudos sejam desenvolvidos com um 'n' maior.

O retorno ao 'normal' já está ocorrendo gradativamente nas escolas ao longo do ano de 2121, mas a pandemia e o isolamento social trouxeram mudanças nas formas de pensar e agir dos professores e alunos.

\section{Referências}

ALMEIDA, L. C.; DALBEN, A. (Re)organizar o trabalho pedagógico em tempos de covid-19: no limiar do (im)possível. Educ. Soc., Campinas, v. 41, e239688, 2020.

ALVES, M. S.; TORRES, A. L. M. M.; JOYE, C. R.; LIMA, M. A. R.; ROCHA, S. S. D. Formação docente em tempos de pandemia: relato de experiência em ensino remoto em uma disciplina pedagógica em instituição federal. Research, Society and Development, Ceará, v. 9, n. 11, e64391110061, 2020.

AMERICAN PSYCHIATRIC ASSOCIATION (APA). Manual Diagnóstico e Estatístico de Transtornos Mentais: DSM-V. 5.ed. Porto Alegre: Artmed, 2014.

BARROS, M. C. S.; MENEZES, A. M. C. Escola e família: desafios e harmonia durante o período pandêmico de 2020 no contexto dos anos iniciais. Rev. Mult. Psi, v.14, n.54, p.222232, 2021.

BRASIL. Ministério da Saúde. Portaria n. 454 de 20 de março de 2020. Declara, em todo território nacional, o estado de transmissão comunitária do coronavírus (covid-19). 2020a. Disponível em: https://www.in.gov.br/en/web/dou/-/portaria-n-454-de-20-de-marco-de-2020249091587. Acesso em: 14 jan. 2021.

BRASIL. Ministério da Educação. Portaria n. 343 de 17 de março de 2020. Dispõe sobre a substituição das aulas presenciais por aulas em meios digitais enquanto durar a situação de pandemia do novo coronavírus (covid-19). 2020b. Disponível em: https:/www.in.gov.br/en/web/dou/-/portaria-n-343-de-17-de-marco-de-2020-248564376.

Acesso em: 14 jan. 2021.

CORREAA, I.; NUNES, S.; DIAS-TRINDADE, S. Uma análise do nível de proficiência digital de professores do ensino médio de escolas públicas estaduais de Palmas - TO. Revista Observatório, v.6, n.1, p.1-24, 2020. 
FONSECA, R. P.; SGANZERLA, G. C.; ENÉAS, L. V. Fechamento das escolas na pandemia de COVID-19: impacto socioemocional, cognitivo e de aprendizagem. Debates em psiquiatria, Rio de Janeiro, v.10, n.7, p.28-37, 2020.

GONCALVES, T. dos S.; CRENITTE, P. A. P. Concepções de professoras de ensino fundamental sobre os transtornos de aprendizagem. Rev. CEFAC, São Paulo, v. 16, n. 3, p. 817-829, 2014.

JOYE, C. R.; MOREIRA, M. M.; ROCHA, S. S. D. Educação a distância ou atividade educacional remota emergencial: em busca do elo perdido da educação escolar em temos de COVID-19. Research, Society and Development, v. 9, n. 7, e521974299, 2020.

LEITE, M. N.; LIMA, E. G. O.; CARVALHO, A. B. G. Os professores e o uso de tecnologias digitais nas aulas remotas emergenciais, no contexto da pandemia da COVID-19 em Pernambuco. Rev. Educ. Mat. e Tec. Ibero, v.11, n.2, 2020.

MEDEIROS, A. Y. B. B. V.; PEREIRA, E. R.; SILVA, R. M. C. R. A. Desafios das famílias na adaptação da educação infantil a distância durante a pandemia do COVID-19: relato de experiência. EaD em foco, v.10, n.3, e1051, 2020.

MORAES, H. L. B.; NASCIMENTO, S. M.; FARIAS, M. A. S.; SANTOS JÚNIOR, G. P. De ensino presencial para remoto emergencial: adaptações, desafios e impactos na pós-graduação. Interfaces Científicas, v.10, n.1, p.180-193, 2020.

SOUZA, G. H. S.; JARDIM, W. S.; MARQUES, Y. B.; LOPES JUNIOR, G.; SANTOS, A. P. S.; LIBERATO, L. P. Educação Remota Emergencial (ERE): um estudo empírico sobre as capacidades educacionais e expectativas docentes durante a pandemia da COVID-19. Research, Society and Development, v. 10, n. 1, e37510111904, 2021.

SOUZA, K. R.; SANTOS, G. B.; RODRIGUES, A. M. S.; FELIX, E. G.; GOMES, L.; ROCHA, G. L.; CONCEIÇÃO, R. C. M.; ROCHA, F. S.; PEIXOTO, R. B. Trabalho remoto, saúde docente e greve virtual em cenário de pandemia. Trab. educ. saúde, Rio de Janeiro, v.19, e00309141, 2021.

UNESCO. Distance learning strategies in response to COVID-19 school closures. UNESCO COVID-19 Education Response. Education Sector issue notes. Issue note n. 2.1. Paris: UNESCO, 2020. 